\title{
Den nicht erzählbaren Anfang der Welt erzählen. Über „Chaos“ und Genesis in Hesiods Theogonie
}

(vorgetragen in der Plenarsitzung am 12. November 2010)

\author{
WILFRIED BARNER
}

Das insistente Fragen nach dem Anfang der Welt, und mitunter auch: das vorwitzige Wissenwollen, was vielleicht noch ,davor' war - zwei der ältesten Spekulationsthemen in vielen Kulturen haben neue Aufmerksamkeit auf sich gezogen, aus zwei recht unterschiedlichen Richtungen: durch die staunenswerten Berichte aus der Weltraumforschung, das heißt aus den Vorstößen ins Universum, und durch die nicht selten hitzigen Debatten um Evolutionismus und Kreationismus, kürzlich wieder aus Anlaß des Darwin-Jahres $2009^{1}$, und mit dem gewissermaßen Dritten Weg des sogenannten "Intelligent Design“ (das manche auch bloß einen faulen Kompromiß schimpfen) $)^{2}$.

In allen diesen Hauptströmungen bleibt jeweils eine Tendenz zum $E r-$ zählen auffällig: bei der Veranschaulichung der gigantischen kosmischen Prozesse und insbesondere beim Reden vom Anfang der Welt. Wo in frühen Weltentstehungsdarstellungen ein Schöpfer geglaubt wird, wie in der biblischen Genesis (1. Mose 1, 1-2), ist für ein zu erzählendes Geschehen zumindest der erste Handelnde, oder der ,erste Beweger' gesichert:

Im Anfang schuf Gott Himmel und Erde;

die Erde aber war wüst und wirr,

Finsternis lag über der Urflut,

und Gottes Geist schwebte über dem Wasser ${ }^{3}$.

$1 \quad$ Hierzu Norbert Elsner: Darwin und kein Ende - Warum? Einige Gedanken am Ende des Darwin-Jahres 2009. In: Jahrbuch der Akademie der Wissenschaften zu Göttingen 2009. Berlin/New York 2010, S. 232 - 250. Dort S. 232 Anm. 1 Hinweise auf weitere aktuelle Publikationen.

2 Kritischer Überblick bei Herbert Jäckle: Biologie der Schöpfung: Darwin oder doch Intelligent Design? In: Evolution. Zufall und Zwangsläufigkeit der Schöpfung. Hrsg. v. Norbert Elsner [u. a.]. Göttingen 2009, S. 438-456.

3 Text nach: Die Bibel. Altes und Neues Testament. Einheitsübersetzung. Stuttgart 1980. 
Die Frage nach dem ,Noch davor' hat eine eigene, intrikate Geschichte ${ }^{4}$. Andersartige, noch schwierigere methodische Probleme stellen sich naturgemäß bei den beteiligten naturwissenschaftlichen Disziplinen. Hierzu, mit nicht professionell abgesichertem Interesse, von außen betrachtet, wenige Beleges.

So formuliert der russisch-belgische Chemie-Nobelpreisträger des Jahres 2003, Ilya Prigogine: „Die Natur präsentiert uns eine Reihe von Erzählungen, von denen eine Bestandteil der anderen ist: die Geschichte des Kosmos, die Geschichte der Moleküle, die Geschichte des Lebens und des Menschen, bis zu unserer persönlichen Geschichte" ${ }^{\text {" }}$. Als eine kategorial noch übergeordnete Frage bei solchen „Erzählungen“ stellt sich (außer der nach dem hier verwendeten Geschichtsbegriff) die viel umstrittene nach der Legitimität und der Funktion wissenschaftlichen Redens in Metaphern, und zwar in Geistes- und in Naturwissenschaften ${ }^{7}$. So sprechen zwei amerikanische Physiker, die sich mit Quantenfeldern im Universum befassen, von einem „Schlachtfeld zweier Kräfte“, der anziehenden und der abstoßenden Gravitation $^{8}$. Oder spezifischer noch, zu unserem Thema „Anfang der Welt", wiederum zwei Kosmologen: „Unmittelbar nach dem Urknall brodelte das Universum"9 - wobei „brodeln“ (bubble) metaphorisch eindrücklich sein mag, aber kaum deskriptiv präzise. Selbst die eingeführte Bezeichnung Big Bang - die man im übrigen auch als den Beginn einer Welterzählung fassen könnte - bewegt sich in der Sphäre des Metaphorischen.

Bei dem hier angesprochenen Fragenkomplex konzentriere ich mich zunächst auf das erwähnte ,Davor' oder ,Noch davor', weil es am direktesten zu Hesiod führt. Für den Astrophysiker, der die Allgemeine Relativitätstheorie im Hinterkopf bewahrt, ist die Frage nur bedingt sinnvoll oder gar gegenstandslos, wenn Raum, Zeit und Materie in einem Akt entstanden sind und somit eine temporale Dimension, für das ,Davor', per se entfällt.

4 Dazu Joachim Ringleben: Creatio ex nihilo. In: J. R.: Arbeit am Gottesbegriff. Bd. 1: Reformatorische Grundlegung, Gotteslehre, Eschatologie. Tübingen 2004, S. 235-248.

5 Außer den bekannten Überblicken in Buchform (Stephen Hawking u. a.) erweisen sich die „Dossiers" der Zeitschrift „Spektrum der Wissenschaft" als aktuell und anregend (wohl auch als zuverlässig).

6 Zit. nach Stefan Klein: Die Tagebücher der Schöpfung. Vom Urknall zum geklonten Menschen. München 2000, S. 10.

7 Aus Platzgründen ein einziger Hinweis: Artikel „Metapher“. In: Enzyklopädie Philosophie und Wissenschaftstheorie. Hrsg. v. Jürgen Mittelstraß. Bd. 2. Stuttgart, Weimar 2004, S. 867 - 870.

8 Jeremiah P. Ostriker u. Paul J. Steinhardt: Die Quintessenz des Universums. In: Spektrum der Wissenschaft. Dossier 01/03, S. 74 - 81; hier: S. 74.

9 Michael Riordan u. William A. Zajc: Die ersten millionstel Sekunden. In: Spektrum der Wissenschaft. Dossier 5/08, S. 40-47; hier: S. 42 f. 
Diese Komplikation ergibt sich zwar für den griechischen Poeten um das Jahr 700 vor Christi Geburt noch nicht. Aber auch ohne das moderne Problem ist die Frage nach dem ,Davor' schwierig genug. Und eine Besonderheit der hesiodeischen Theogonie wurde schon in der Antike darin gesehen, daß sie hieraus eine - gewiß aporetische - eigene Antwort zu geben versucht. Kein Geringerer als Aristoteles hat sich in seiner Physik mit diesem „Anfangs“-Passus der Theogonie ausdrücklich befaßt ${ }^{10}$.

Die Theogonie (wörtlich: „Götterentstehung") ist in der europäischen Überlieferung der älteste Weltentstehungstext, der zuallererst, oder besser: ineins damit, einen Götterentstehungstext darstellt. Es handelt sich um ein über tausend Hexameterverse umfassendes Großgedicht noch aus der Periode Homers, jedenfalls des - im Verhältnis zur Ilias - jüngeren Epos Odyssee $^{11}$. Nach einer sehr genau ausgearbeiteten zweiteiligen Einleitungspartie, die wesentlich den Musen gewidmet ist (sogenanntes Proömium), entfaltet sich das, was man die ,Kern-Theogonie' nennen könnte: die genesis ${ }^{12}$ der Götter und zugleich in ihr der, Welt'. Gleich der erste Vers (v. 116) ,setzt', noch vor der Nennung einer ersten Gottheit überhaupt, das Wort „Chaos", umstandslos und ohne jede Erläuterung:

Wahrlich, zuallererst entstand

Die gähnende Leere (Chaos),

Alsdann aber die Erde (Gaia) mit ihrer breiten Brust ${ }^{13}$.

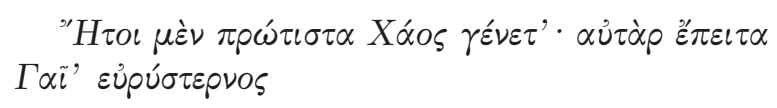

Neben der unvermittelten ,Setzung' des Worts „Chaos“ fällt - vielleicht irritierend - auf, daß dieses griechische Wort hier sowohl Bezeichnung (,gähnende Leere") als auch Name sein kann ${ }^{14}$. Das handschriftliche Original ist durchgängig in Versalien gehalten, unterscheidet also nicht nach Groß-

10 Unter wörtlicher Zitierung der ersten anderthalb Zeilen: Physik 208 b 25 ff.

11 Die seit über zweihundert Jahren heiß diskutierten Probleme der Chronologie müssen hier ausgeklammert bleiben.

12 Dieses bekannte griechische Lexem beruht auf dem gleichen Stammwort (aber mit Ablaut) wie das Kompositionsglied -gonie.

13 Hier und im folgenden ist unter den zahlreichen deutschen Übersetzungen - als besonders ,textnah` - diejenige von Walter Marg zugrunde gelegt: Hesiod: Sämtliche Gedichte. Übers. u. erläut. v. W. M. Zürich u. München ${ }^{2}$ 1984. Die in runden Klammern stehenden Namen, vom Übersetzer hinzugefügt, sollen in Umschrift die originale griechische Schreibung wiedergeben. Griechische Zitate nach: Hesiodi Theogonia Opera et Dies [ . . ] ed. Friedrich Solmsen. Oxford 31990.

14 Siehe den einschlägigen Artikel im LfgrE [wie Anm. 17]. Die zahlreichen Überblicksartikel und Monographien zu „Chaos“ verzeichnet auf neuerem Stand (und mit betont ,modernem' Interesse) Bianca Theisen: Artikel „Chaos - Ordnung“. In: Ästhetische Grundbegriffe. Historisches 
und Kleinschreibung ${ }^{15}$. Zu einer ,Gottheit ' fehlt jegliche einschlägige Prädizierung. Und, bei „Urwesen“ (worunter man Chaos sowie die bald darauf genannten Eros und Gaia gelegentlich subsumiert hat - dazu später) ist notwendigerweise kritisch zu fragen, ob dieses „Wesen“ hier überhaupt schon als Entität identifizierbar ist. Und dieses Chaos „entstand“. Die sich aufdrängende Frage, Woraus?' bleibt unbeantwortet, geht ins Leere. Es ist eine Sprachgeste des ,Aussparens' oder auch ,Verschweigens', die in manchen frühen Mythentexten begegnet, etwa bei (aus unserer Sicht) akausalen Vorgängen, beispielsweise plötzlichen Gestaltwandlungen (Metamorphosen) ${ }^{16}$.

Für die Frage nach der Erzählbarkeit des Anfangs ist von Belang, daß die zunächst isolierte Wendung „entstand“, wenn man weiterliest, in eine Reihe von Akten des ,Erzeugens' und ,Geborenwerdens' oder ,Entstehens einrückt. Sie bildet sozusagen das Rückgrat für die Erzählstruktur der ,KernTheogonie insgesamt. Gottheit auf Gottheit folgt, bald schon genealogisch verzweigt und in abgestuften Generationen und Hierarchien. An der morphologischen Oberfläche wird das ablesbar in der klaren Dominanz von Ableitungen aus griechisch gen und (der Ablautform) gon, zusätzlich von Wendungen etwa für ,zeugen' und ,Zeuger' (tek, tok). Abgekürzt ließe sich von einem „generativen Faden“ sprechen, der dieses mythische Erzählen ermöglicht, auch ,Abzweigungen“ und dergleichen (daß die z.T. aus dem Lateinischen abgeleiteten Wendungen wie generativ, genetisch, Generation usw. ähnliche Muster zeigen, ist kein Zufall).

Der zunächst irritierende „Chaos"-Anfang (irritierend ob seiner Unvermitteltheit und inhaltlichen Unbestimmtheit) wird durch das rätselhafte „entstand“ (egeneto) von rückwärts her an eine Erzählgroßstruktur angebunden. Zwei weitere für den „Anfang“ spezifische Beobachtungen. Die allererste, für „wahrlich“ stehende griechische Partikel (so schon in der Ilias begegnend) hat feierlich versichernden, bekräftigenden, ,Wahrheit ankündigenden Charakter. Und „zuallererst“ ist im Original als Superlativ von "zuerst“ gebildet - rein aussagenlogisch hypertroph und somit, wie die anderen genannten Merkmale, auf ,archaische', oder auch ein-

Wörterbuch in sieben Bänden. Hrsg. v. Karlheinz Barck [u. a.]. Bd. 1. Stuttgart, Weimar 2000. S. 751-771,

15 Die moderneren Ausgaben der Theogonie setzen zumeist einen Großbuchstaben in den Beginn des Worts (wie bei Namen oder bei ,Personifikation'), überdecken somit notgedrungen das Problem.

16 Solchen und ähnlichen Merkmalen (wie ,Verschweigung', Überexaktheit, Dingsymbolik, List, historische Transformation u. dgl.) in sehr frühen Dokumenten wie - auffälligerweise - in modernen Texten seit Nietzsche, geht ein eigenes Buchprojekt nach, das den Arbeitstitel trägt: Mythen lesen. Elemente einer Phänomenologie. 
fach unbeholfene Weise das Außerordentliche dieses Erzählanfangs ausdrückend ${ }^{17}$.

Mit „Gaia“ (v. 117) erscheint, als eines der ,Urwesen', die erste Göttin, mit eindeutig personaler Dimension. Im Kontrast zum unbestimmt bleibenden Chaos wird sie handeln, Kinder gebären (Vater oder Mutter bleiben freilich, wie bei Chaos und dann bei Eros, ausgeblendet; das konstituiert sie als ,Urwesen'). Sie ist, nach der in vielen Kulturen verbreiteten Vorstellung, ,Mutter Erde ${ }^{18}$. Für Hesiods Konzept vom „Anfang der Welt" fast noch belangreicher: Sie ist erkennbar auch bereits Teil der materiellen, Welt'. Sie ist, wie es gleich anschließend heißt (v. 119), „fort und fort sicherer Sitz von allen" (Lebewesen). In ihr repräsentiert sich bereits die Einheit von Theogonie und Kosmogonie. Sie trägt das Land (auch das Meer) und insbesondere - bei Hesiod wiederholt herausgehoben - die „hohen Berge“, in denen die physische Mächtigkeit der Erde sichtbar wird (es ist wohl nicht zu weit gegriffen, hier auch das Heranwachsen Hesiods am Fuß des über 1700 Meter aufragenden Musenberges Helikon als mitprägend zu vermuten). Es entsteht Gaia „mit ihrer breiten Brust“": bemerkenswert, daß das hier im Original gewählte Adjektiv (wörtlich: „breitbrüstig“) mit dem Kompositionsglied „Brust“ schon in der Ilias weit überwiegend die männliche Brust bezeichnet; eine Übersetzung „mit ihren breiten Brüsten“ wäre also durchaus unangemessen. Am Rande, bezugnehmend auf eine moderne Theorie, mag daran erinnert werden, daß diese Auffassung von der Erde als „Sitz“, als Lebensraum „von allen“, in den 1960er Jahren als sogenannte „Gaia-Hypothese“ von Lynn Margulis und James Lovelock die Erde und ihre gesamte Biosphäre wie ein „Lebewesen“ interpretierte: im Sinne der Gesamtheit aller Bedingungen für „Leben“"19.

Die knappen, gedrängten Anfangsverse der ,Kern-Theogonie`, mit ihren absichernden („Wahrlich“) und zugleich ins Weiteste ausgreifenden (,zuallererst“) Sprachgesten reflektieren etwas vom Anspruch, von der gewaltigen Dimension des Unternehmens, den Anfang der Götter und der Welt zu erzählen. Nach griechischen Begriffen ist es ein Vorhaben, das sich in der Nähe der hybris bewegt. Gewiß, die Berufung auf die Musen, die Töchter des höchsten Gottes, Zeus, öffnet eine Möglichkeit der Rückverge-

\footnotetext{
$17 \mathrm{Zu}$ den semantischen Fragen des griechischen Originals hier und im Folgenden (wegen der leichten Auffindbarkeit der Lemmata nicht wiederholt genannt): Lexikon des frühgriechischen Epos [LfgrE]. Begründet v. Bruno Snell. Hrsg. im Auftrag der Akad. d. Wiss. zu Göttingen. Bd. 1-4. Göttingen 1955-2010.

18 Daß hier zugleich, wie auch bei späteren Vorstellungsmustern (,Große Mutter', ,Mutter Kybele u. a.), mannigfaches altorientalisches Substrat vorliegt, kann nur erwähnt werden.

19 Der hier fachlich zuständige Kollege Gerhard Wörner, der in der Akademiesitzung anschließend referierte, hat das Thema (wie er mir sagte) aus Zeitgründen ausgeklammert.
} 
wisserung, der Legitimation. Sie geht über die Kürze und Formelhaftigkeit der aus Ilias und Odyssee bekannten Musenanrufe weit hinaus. Sie exponiert, viel spezifischer, in diesen 115 Versen des Proömiums, zugleich das historische Individuum Hesiod. Das macht wenige Kontexterläuterungen unumgänglich ${ }^{20}$.

Das außerordentliche Ich-Bewußtsein, wenn nicht gar der Stolz dieses Poeten manifestiert sich schon in der Tatsache, daß er in der abendländischen Überlieferung als erster Autor mit Nennung des eigenen Namens (Hesiodos) vor sein Publikum tritt (Theogonie, v. 22), freilich nicht als ,Ich', sondern als ,Objekt' der Berufung durch die Musen (im Akkusativ). In seiner nächst der Theogonie bekanntesten Dichtung, den Werken und Tagen (die man einen am Jahreslauf orientierten „Bauernkalender“ genannt hat, mit zahlreichen auch mythischen Erzählungen), verficht er durchaus handfest persönliche Belange, in einem Erbrechtsstreit mit seinem Bruder Perses. Hesiod ist einer der frühesten ausgeprägten ,Rechtsdenker ' der Griechen - was für sein ,Ordnungsdenken' von einigem Belang wird (dazu weiter unten im Zusammenhang seiner Kosmosvorstellung). Die bäuerlichagrarische Herkunft aus dem Dorf Askra wird als prägend nicht nur in der Berufung des „Hirten“ Hesiod durch die Musen erkennbar (aus einer Schar von Schafhirten heraus, v. $22 \mathrm{ff}$.), sondern auch in der schon angesprochenen besonderen Gaia-Verbundenheit. Sie ist eine Determinante seines, Welt'-Bildes. Seine Heimat, das mittelgriechisch-festländische Boiotien, steht zweifelsohne in charakteristischem Kontrast zur ostionischen, seeorientierten, westkleinasiatischen Kultursphäre, also auch zu derjenigen Homers (tendenziell adelsgeprägt) und der homerischen Epen. Die Region Boiotien insgesamt gehört, insbesondere in der Heterostereotypen-Perspektive der Athener, eher dem Typus Ostfriesland oder auch Niederbayern an. Was die faktische Weltkenntnis Hesiods angeht (Geographie, Erzählüberlieferung und dergleichen), so mag die Herkunft des Vaters aus dem nordwestlichen Anatolien an der Ägäisküste - wo er sich im Seehandel versucht hatte - eine Rolle spielen.

Hesiod wird in die Periode der frühgriechischen Kolonisation hineingeboren (um 750 - um 550 v. Chr.), durch die sich die Erfahrungswelt der

20 Aus der sehr umfangreichen internationalen Literatur zur Einführung nur der aktuelle Artikel „Hesiodos“ in: Der Neue Pauly. Hrsg. v. Hubert Cancik u. Helmuth Schneider. Bd. 5. Stuttgart, Weimar 1998, Sp. 506-510. Ausgezeichneter Kommentar zur Theogonie: Hesiod: Theogony. Ed. with Prolegomena and Commentary by Martin L. West. Oxford ${ }^{2} 1971$. Für deutschsprachige Leser gut zugänglich, in den „Anmerkungen“ ungleichmäßig: Hesiod. Theogonie. Griechisch/Deutsch. Übers. u. hrsg. v. Otto Schönberger. Stuttgart 1999. Für zuverlässige Mithilfe in Sachen Hesiod danke ich Jonathan Groß. 


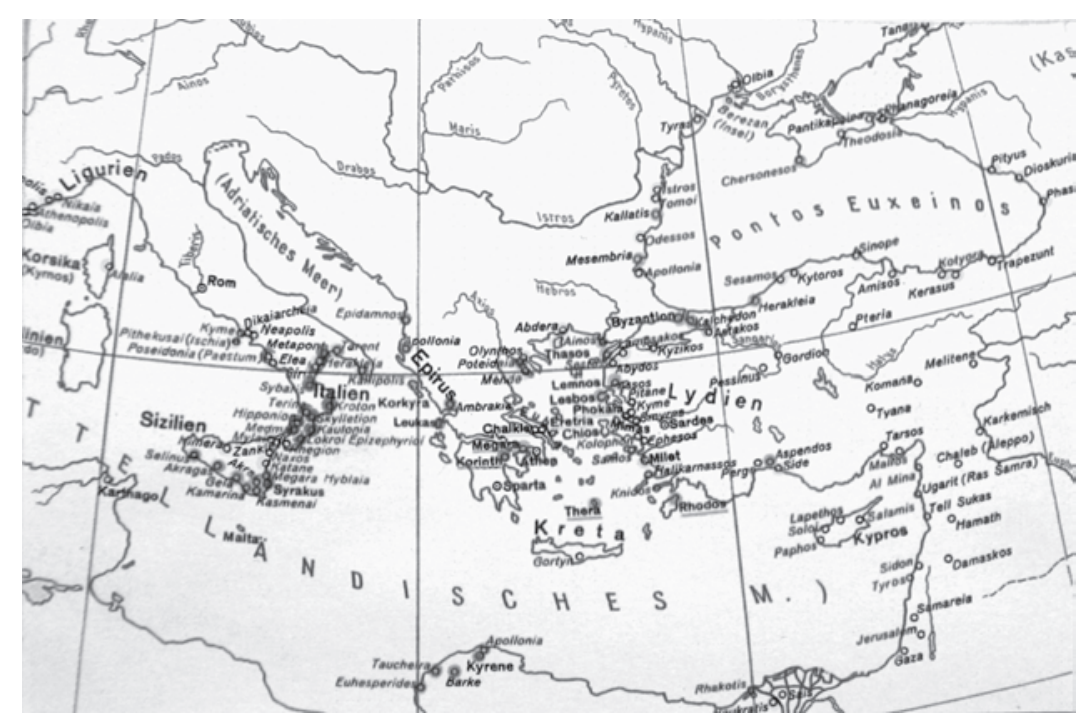

Abbildung 1: Die Mittelmeerwelt zur Zeit der Großen griechischen Kolonisation (um 750-um 550 v. Chr. $)^{21}$.

Griechen, auch die Vorstellungswelt der Festlandsbewohner, erheblich erweiterten und differenzierten. Die Erkundungszüge erstreckten sich praktisch über das gesamte Mittelmeer (im Westen bis nach Gibraltar, den „Säulen des Herakles") und darüber hinaus (von der Krim bis ins Niltal):

So, wie später die Historien des Ioners Herodot manifester Niederschlag seiner weiten Reisen vor allem im Osten wurden (von 450-430 v. Chr.), hat man für die Odyssee mit guten Gründen auch Reflexe der frühen Kolonisation vermutet. Es ist vielleicht keine abwegige Spekulation, daß die Theogonie, aus der Epoche der Odyssee, einen gewissermaßen komplementären festländischen Antwortsversuch auf die Frage nach dem ,Woher?' dieser neu erschlossenen „Welt" darstellen könnte. Dies in prinzipiell erzählender Form (daß dabei auch vorgriechisch-mittelmeerische resp. vorderorientalische Muster mit im Spiel waren, bleibt durchaus eingeschlossen) ${ }^{22}$.

Die handwerkliche Grundlage für die Verfertigung einer hexametrischen Komposition wie der Theogonie, auch für ihre narrativen Techniken, vermittelte das Metier der Rhapsoden: fahrende Sänger, wie es sie auch in

\footnotetext{
21 Abbildung nach: Grosser Historischer Weltatlas. Hrsg. v. Bayerischen Schulbuchverlag. 1. Teil. Bearb. v. Hermann Bengtson u. Vladimir Milojcic. München ${ }^{4}$ 1963, S. 12.

$22 \mathrm{Zu}$ diesem besonders aktuellen Komplex am besten Walter Burkert: Die Griechen und der Orient. München ${ }^{3} 2009$ (eingehender auch zu Hesiod, besonders zu seiner „Kosmogonie“).
} 
anderen Kulturen gibt (nordische Skalden, balkanische Gusle [oder Guslaren] bis ins 20. Jahrhundert, u. a.), die öffentlich auftraten, mitunter auch im Wettbewerb gegeneinander. Bei Homer begegnen solche Gestalten (etwa Demodokos bei den Phaiaken in der Odyssee), die ihren Gesang mit der Leier begleiten. Bei Hesiod ist eher Rezitation mit (skandierendem, unterstreichendem) Stab anzunehmen.

Für ein so ehrgeiziges, fast hybrishaftes Wagnis wie die Theogonie sind uns keine unmittelbaren Vorbilder bekannt. Große Taten von Göttern und Helden erscheinen im Text nur vereinzelt, meist anspielungsweise. Neben dem (narrativen) Epos beherrschten die Rhapsoden auch das - meist kultisch gebundene - Götterlied, den Hymnos. Unter Homers Namen überliefert ist ein ganzes Corpus von Hymnen, von denen die ältesten bis ins 7. Jahrhundert zurückreichen, und einige sogar mehrere hundert Hexameter umfassen: Apollon-Hymnos 546 Verse, Hermes-Hymnos 580 Verse; kürzere dienten lediglich als Proömien zu anderen. Hier vor allem knüpft Hesiod an. Einige dieser Lieder enthielten umfangreiche, erzählende` Partien, mit der Schilderung großer Taten der einzelnen Gottheiten, mit dem Preis ihres segensreichen Wirkens, und ähnlichem. Hesiod schafft - hierin durchaus ,originell ${ }^{\leftarrow}$ - etwas Eigenes, Drittes: ein fast überdimensionales Götterlied, aber nicht auf eine Gottheit, sondern auf die Genesis der Götter schlechthin. Es geschieht mit den auch in den Hymnen verwendeten, integrierten Erzählmöglichkeiten, nicht zuletzt mit Nutzung einzelner homerischer Erzähltechniken (samt Szenerie, Dialogführung etc.) aus der Ilias und der Odyssee 23 .

Doch wie erklärt sich bei Hesiod, etwas grundsätzlicher gefragt, dieser offenkundige Drang zum Erzählerischen? Gibt es nicht, gerade bei religiösen Gegenständen, die Möglichkeit der sinnlich reichen, visionären Vergegenwärtigung im Bild (das freilich in nicht wenigen Kulturen - gerade auch der griechischen - vielfältige Formen der ,Bilderzählung' entwickelt hat)? Die komplexe Frage sei hier auf zwei Kernpunkte konzentriert. Der eine liegt in der sozusagen anthropologischen Verankerung des Erzählens begründet, abgekürzt: der Mensch als homo animal narrans. Die neuere Erzähltheorie oder Narratologie ${ }^{24}$ hat differenzierter die kognitiven, auch die ,ordnenden' Funktionen bestimmter Erzählweisen herausgearbeitet. Wie beim deutschen „er-zählen“ enthalten die meisten griechischen Synonyme hier-

23 Markus Janka: Fokalisierung und Mythenkritik in Hesiods Theogonie. In: Frühgriechisches Denken. Hrsg. v. Georg Rechenauer. Göttingen 2005, S. 40-62 (der etwas mißverständliche Titel läßt das hier einschlägige Thema nicht erkennen).

24 Überblick über die internationale Entwicklung besonders seit den 1960er Jahren: Matias Martinez/Michael Scheffel: Einführung in die Erzähltheorie. München ${ }^{8} 2009$. 
für Momente von „aufsammeln“, „aufzählen“, „aneinanderreihen“, „verknüpfen“, „in die Reihe bringen“. Darin stecken Ansätze zum ,Ordnen“, ,Klären ${ }^{25}$. Der zweite Kernpunkt: Bei Hesiod handelt es sich (wie bei Homer) um mythisches Erzählen. Angesichts dieses heute einen semantischen Alltags- und Massenmediendschungel darbietenden Begriffs kann nur auf einen gut orientierenden Artikel verwiesen werden ${ }^{26}$. Erwähnt sei jedoch exemplarisch ein frühmoderner Kronzeuge für den Wechsel in der Bewertung der antiken Mythen. Francis Bacon (1561-1626) hat sich bekanntlich auf der Basis seiner neuen „Erfahrungswissenschaft“ auch um ein Erkenntniskonzept für Phänomene der vita humana und der äußeren natura bemüht. In seiner Schrift „Von der Weisheit der Alten“ (De sapientia veterum, 1609) setzt er dazu an, die antiken Mythen von dem herrschenden Präjudiz als bloßer Fiktion oder gar Täuschung zu befreien (die Wurzeln zu dieser Abwertung liegen bereits in der Antike selbst). Er sieht in ihnen vielmehr eine frühe Form der Natur-Erkenntnis, eine auch rationale Dimension; und er deutet - am Beispiel des Orpheus - sogar eine Tendenz zur Naturbeherrschung $\mathrm{an}^{27}$. Man braucht so weit nicht zu gehen. Für Hesiods Theogonie erweist sich das ,Erzählen' angesichts der übermächtigen theogonischen und kosmogonischen Vorgänge zumindest als eine plausible Interpretation (ob sich für das moderne ,Erzählen 'von Prozessen des Universums vergleichbare Motive der ,Bewältigung' oder auch der ,Distanznahme' ansetzen lassen, bleibe dahingestellt).

An dieser Stelle unserer Überlegungen erscheint es als sinnvoll, für grundsätzlich alles Erzählen vom „Anfang der Welt“ drei Fragen zu formulieren.

- Erstens: Was, inhaltlich gefaßt, läßt sich - wenn überhaupt - vom Anfang der Welt erzählen?

- Zweitens: Wie, in welchem Modus, kann man davon erzählen (und es nicht etwa, lediglich visionär, imaginieren)?

- Drittens: Wie steht es mit der Verbürgtheit dieses undenkbar Fernen, des Anfangs, von dem erzählt wird; das heißt zuletzt: Wie steht es mit der Frage der Wahrheit?

\footnotetext{
25 Dem hierzu konträren Muster, dem „unzuverlassigen Erzähler“, hat die neuere Erzähltheorie seit Wayne C. Booth mit gutem Recht stärkere Aufmerksamkeit gewidmet.

26 Aleida u. Jan Assmann: Artikel „Mythos“. In: Handbuch religionswissenschaftlicher Grundbegriffe. Hrsg. v. Hubert Cancik [u. a.]. Bd. 4. Stuttgart [u. a.] 1998, S. 179-200.

27 Das Wichtigste im Zusammenhang der Theoriegeschichte bei Christoph Jamme: „Gott an hat ein Gewand“. Grenzen und Perspektiven philosophischer Mythos-Theorien der Gegenwart. Frankfurt a. M. 1991, S. 88 ff.
} 


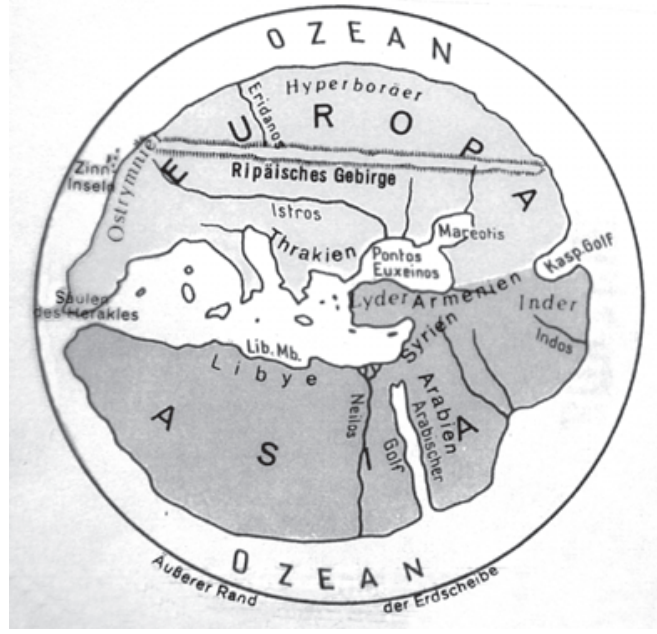

Abbildung 2: „Erdkarte“ des Hekataios $^{28}$.

Die drei Fragen können behilflich sein, der Besonderheit der Theogonie auch im Hinblick auf nicht schon ,erledigte' Problemstellungen (oder auch éternelles questions) wie dem „Davor" oder dem "Chaos“ näher zu kommen. Frage eins impliziert, wenn man weiterdenkt, die Frage nach dem jeweiligen „Ist“, nach der Vorstellung von dem, was jetzt ist, als das auch materielle Resultat jenes Prozesses, der mit dem Anfang begann. Es ist das Weltbild in einem sehr wörtlichen Sinn. Mit dem bei den Griechen ältesten rekonstruierbaren - natürlich umstrittenen - Zeugnis gelangt man, wiederum über dessen nachweisbare Vorlage, immerhin bis in die Anfänge des 6. Jahrhunderts vor Christus zurück und damit in die bereits weit fortgeschrittene Kolonisationsära. Es ist die sogenannte „Weltkarte“ oder genauer „Erdkarte“ des Hekataios aus Milet, dem an der südwestanatolischen Ägäisküste liegenden frühen Zentrum der - vor allem die Seewege erschließenden - Naturkunde und der spekulativen Naturphilosophie. Als bekannteste Namen seien der ,Philosoph' und Mathematiker Thales (um 650-um 560), sein Schüler Anaximander (um 610-546), Kosmologe und Naturphilosoph mit dem ersten Versuch einer „Erdkarte“, und Hekataios genannt (um 555-nach 500): weitgereister, Geschichtsschreiber' (in Prosa), Genealoge und ,Erdbeschreiber' (auf Anaximander aufbauend).

Die Beiziehung dieser Rekonstruktion dient lediglich der Illustration eines möglichen Komplements eines „Ist“ zum „Wurde“. Akzeptiert man

28 Rekonstruktion nach: Grosser Historischer Weltatlas [wie Anm. 21], S. 8. 
diese Hilfsfunktion, so ist die Konvergenz in einigen Grundpunkten bemerkenswert.

Zur Karte des Hekataios drei hauptsächliche Hinweise. Zunächst: Die Erde, Gaia, ist vorgestellt als ungefähr kreisrunde Scheibe ${ }^{29}$, die Land und Meer einschließt und (was in der Theogonie durch die wiederholt erwähnten "hohen Berge“ hervorgehoben wird) mit dem „Ripäischen Gebirge“ gewissermaßen die physikalische Vertikale auf der Gaia betont. (Im übrigen begegnet hier eines der frühesten Zeugnisse für die - nördlich/südliche sozusagen kartographische Trennung in Europa und Asien.) Sodann: Das Ganze wird durch einen gewaltigen Ringfluß umschlossen (zu dem es ein recht genaues babylonisches Analogon gibt, dort „Bitterfluß“ genannt). Dieser Bedeutung durchaus entsprechend, wird Okeanos - so heißt er schon in der Ilias - von Gaia (nach dem "gestirnten Himmel" [Uranos, v. 127] und dem „unwirtlichen Meer“ [pelagos, v. 131] als dritter geboren: „tiefwirbelnd“; auch dies bei Homer vorgebildet. In ihn fließen zuletzt alle Flüsse, auch der Indos und der Nil und der Ister (d. h. die untere Donau): eine ,Letztvereinigungs'-Vorstellung, die Hölderlin besonders fasziniert hat. Und drittens: Vom griechischen Siedlungszentrum aus erschließt sich die Erde über das Mittelmeer, bis zu den Säulen des Herakles. Das Ganze ist - dies bedarf keiner zusätzlichen Begründung - zugleich eine Spiegelung der frühen griechischen Kolonisationserfahrungen, einer Epoche, die zu Hesiods Lebenszeit schon voll entfaltet war und die den Hekataios (erst recht sein Vorbild Anaximander) noch einschlo $\aleph^{30}$.

Die Frage nach dem „Ist“, gestellt aus Anlaß einer Kontextualisierung der Theogonie, erweist sich für die ,Karte' des Hekataios zunächst, wie nicht anders zu erwarten, als eine nach der Vorstellung von diesem „Ist“. Sie artikuliert sich in der visuellen Präsentation eines ,Bildes', dessen wichtigste Bestandteile, wie Gaia, Okeanos, das Meer usw., gleich im Anfang der ,Kern-Theogonie` als narrative Elemente begegnen. In diesem generellen Sinn ,bestätigen' sie einander (es wäre jedoch abwegig, etwa nach dem Indos oder dem Ripäischen Gebirge zu fragen, die bei Hesiod nicht vorkommen). Eine entscheidende Differenz, in der die Eigenart des hesiodeischen ,Erzähl'-Versuchs zu ihrem Recht kommt, wird in einem charakteristischen Anspruch des Hekataios erkennbar: seinem Pochen auf Empirie durch weite Seereisen, mit ,Selbersehen' (griechisch opsis), und durch vorliegende

\footnotetext{
29 Schon Heraklit postulierte die Kugelform überwiegend mit Argumenten aus der Beobachtung von Mondfinsternissen. Platon bestätigte die These mit weiteren Argumenten.

30 Zu ihm der Artikel „Hekataios aus Milet“ in: Der Neue Pauly [wie Anm. 20]. Bd. 5. Stuttgart/Weimar 1998, Sp. 264-267.
} 
Seefahrerhandbücher sowie durch Befragen anderer $(a k o e ́)^{31}$. Diese grundlegende ,Referenz'-Geste führt sowohl auf die zweite wie die dritte Hauptfrage, die beide über die Empirie (im Sinne des Hekataios) hinausreichen und sich dem Problem der eigentlichen ,Nichterzählbarkeit' aussetzen. Die ersten vier Verse (v. 1-4; der Titel „Theogonie“/ ӨЕОГОNIA bleibe hier ausgeklammert $)^{32}$ :

Von den Musen des Helikon

Laßt uns beginnen zu singen,

Sie, die des Helikons Höhe bewohnen,

Die mächtige, gotterfüllte,

Und um die veilchendunkle Quelle

Tanzen sie mit zarten Füßen,

Und um den Altar des hochmächtigen Kronossohnes (Zeus).

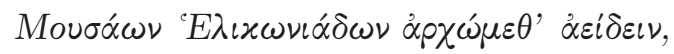

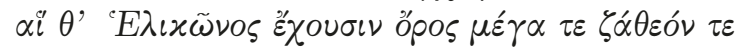

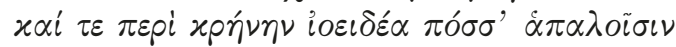

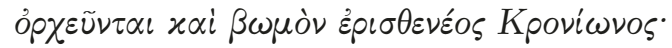

Mit diesem Eingang beantwortet Hesiod (oder ,der Text') die Frage nach dem „Wie?“, nach dem Modus des Erzählens vom Anfang, für die zeitgenössischen Zuhörer (später: Leser) sofort eindeutig: Es ist das „Singen“ eines Götterliedes (bymnos; das Verb hierzu begegnet schon in v. 11). Genau im Stil der erwähnten ,homerischen' Hymnen beginnt mit einem charakteristischen Relativsatz ${ }^{33}$ das Erzählen von ihrem Wirken, ihrem Treiben in der Natur. Die lokale - für Hesiod: heimatliche -, die topographische Fixierung nennt nicht irgendeinen Ort, sondern den hohen Berg der Musen mit der heiligen Quelle und dem Zeus-Altar. Die kultische Anbindung ist evident. Wie mit „Tanzen“ und „Reigen“ und zarten Details eine narrative ,Szenerie' entfaltet wird, mag etwa an die Nausikaa-Szene in der Odyssee (im 6. Gesang) oder ähnliches erinnern.

Ziemlich genau in der Mitte (v. 10-12) dieses ersten Eingangsteils (v. 1-21) schwenken die Verse um zum Inhalt dessen, was die Musen selbst singen (also bereits eine spiegelnde, Tiefenstaffelung'): Sie preisen die Götter, von Zeus und Hera und Athene und Artemis über Themis und

31 Für die frühe Geschichtsschreibung wird dies methodisch vor allem durch den Ioner Herodot (ostmittelmeerisch orientiert) weiterentwickelt.

32 Der Titel dürfte - wie bei den meisten Texten dieser frühen Zeit - erst später hinzugesetzt worden sein.

33 Der hierfür (wie für viele nichtgriechische Götterlieder) eingeführte Spezialbegriff „Relativprädikation" stammt von Eduard Norden. 
Aphrodite und Helios (Sonne) und Selene (Mond) und Okeanos (!) bis zur „dunklen Nacht“. Das Ganze ist, wohlkalkuliert, eine gedrängte narrative ,Vorwegnahme' (Prolepse) ${ }^{34}$ des Gesamten, sozusagen eine ,Kleine Theogonie‘. Das „Wie?“, der Modus ist in den entscheidenden Umrissen bestimmt: Götterlied, Preisen, Singen mit mannigfaltigen Möglichkeiten erzählerischer ,Ausgestaltung'.

Ein zweiter, etwas kürzerer Eingangsteil (v. 22-34/35) wechselt mit deutlicher Zäsur, durchaus zielgerichtet, von „den Musen“ zu „(dem) Hesiod“:

Diese Göttinnen haben eines Tages

Hesiod schönen Gesang gelehrt,

Wie er die Schafe weidete

Am Hang des gotterfüllten Helikon.

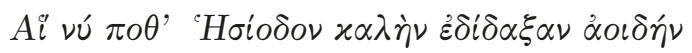

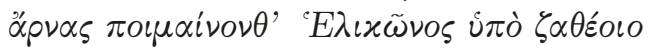

$\mathrm{Da}$ Hesiod (Hesiodos) sich hier - als erster europäischer Poet - mit Namen selbst einführt, freilich als, Objekt' (im Akkusativ) der Musenansprache, wurde schon erwähnt. Jetzt tritt er, als Individuum, in die Kette des göttergegebenen Gesangs ein: was die „schöne“ Form angeht und - wie sich gleich zeigen wird - auch die "Wahrheit“ im Sinne der dritten oben formulierten Grundfrage. Er wird, durchaus dem biblischen David vergleichbar, als Sänger aus der Schar der Hirten herausgehoben. Diese Szene wurde zum Urmuster zahlloser ,Dichterberufungen' in der Weltliteratur (nicht selten unter ausdrücklichem Bezug auf Hesiod). Das hybrisnahe Wagnis auch einer Theogonie ist eines mit der Autorität, dem Vermögen der Zeus-Töchter. Sie haben ihn den schönen Gesang nicht nur „gelehrt", sondern ihm auch, wie es kurz darauf heißt (v. 31), eine göttliche Stimme „eingehaucht“ (es ist genau das Wort, dessen lateinisches Äquivalent inspiratio lautet).

Fast überraschend ist, was die Musen den Hirten in wörtlicher Rede offenbaren (v. 27 f.):

Wir wissen trügenden Schein in Fülle zu sagen,

Dem Wirklichen ähnlich,

Wir wissen aber auch, wenn es uns beliebt,

Wahres zu künden.

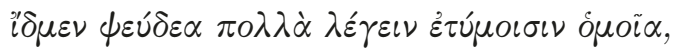

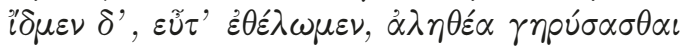

34 Über diesen neueren Terminus (von Gérard Genette) s. Martinez/Scheffel [wie Anm. 24], S. $36 \mathrm{f}$. 
Man hat hierin wiederholt - und sicher zu Recht - ein sehr frühes explizites Zeugnis für das Bewußtsein vom „Fiktions“-Charakter der Poesie gesehen. Nicht weniger belangvoll ist die Warnung vor der Willkür der Götter (hier ein wenig ,postmodern': „wenn es uns beliebt“). Könnte es nicht im Nebensinn auch einen ,salvatorischen' Bezug auf das neuartige, ehrgeizige Projekt der Theogonie insgesamt enthalten, auch etwa auf die ,Nichterzählbarkeit des „Anfangs der Welt“? Die enormen Ausdrucksschwierigkeiten zu Beginn der ,Kern-Theogonie` waren ja unverkennbar.

Den inhaltlichen Auftrag der Musen an den Sänger faßt Hesiod als „,rühmen“ (im Griechischen das Verb, durch dessen Stamm auch der Name der Muse „Kleio/Klio“ gebildet ist): „was sein wird Und was vorher gewesen“ (v. 32; etwas später, in v. 38, vervollständigt sich die Formel durch das „was ist “ zur Dreiheit). Es ist eine recht abstrakte, wahrhaft universale Fassung, in die neben dem Götter- und Heldensänger auch Züge des göttlichen Sehers einbezogen sind (bereits von Homer her nicht unvertraut).

Neben dem „schönen Gesang“ verleihen die Musen dem Hesiod als äußere, auszeichnende Symbole auch „den Stab des Sprechers“ (v. 30), entsprechend der Entwicklung zur Zeit Hesiods (also nicht mehr die Leier), und: „Des stark sprossenden Lorbeers Zweig“ (v. 30). Hesiods Musenproömium zur Theogonie exponiert in der europäischen Dichtungstradition nicht nur zum ersten Mal die neun Musen, sondern auch die Namen (die heute verwendeten ,Bereichs'-Zuweisungen, auch die der Klio, stammen aus viel späterer Zeit - was mitunter nicht bedacht wird).

Für den Versammlungsraum der Göttinger Akademie der Wissenschaften, wie er 1837 zum hundertjährigen Jubiläum der Universität nach dem Konzept von Carl Otfried Müller ausgestaltet worden ist, stellt das Musenproömium der Theogonie Hesiods den ältesten Bezugstext überhaupt dar ${ }^{35}$. Ein einziges Beispiel, der „Musenführer“ Apollon, lorbeerbekränzt, Kithara spielend, in fast weiblicher Körperausformung (Abbildung 3):

Der Lorbeerbaum, seit früher Zeit dem Apollon zugehörig (die DaphneSage wurde eigens zur aitiologischen Fundierung geschaffen) bot mit seinen Zweigen Auszeichnungssymbole für Dichter und Sänger (deren Schutzgott Apollon war), auch für Sieger bei den Pythischen (Delphischen) Spielen. In der römisch-lateinischen Tradition kam unter anderem die Lorbeerehrung

35 Zur wissenschaftsprogrammatischen Konzeption, besonders auch für Göttingen: Rudolf Horn: Das Sitzungszimmer der Akademie der Wissenschaften zu Göttingen. Eine Studie zum Nachleben der antiken Malerei. In: Jahrbuch der Akademie der Wissenschaften in Göttingen. Übergangsbd. für die Jahre 1944-1960. Göttingen 1960, S. 68-101. Die größeren Zusammenhänge kurzgefaßt in: Marianne Bergmann, Christian Freigang, Stephan Eckardt: Das Aula-Gebäude der Göttinger Universität. Athen im Königreich Hannover. München 2006, bes. S. 28-48. 


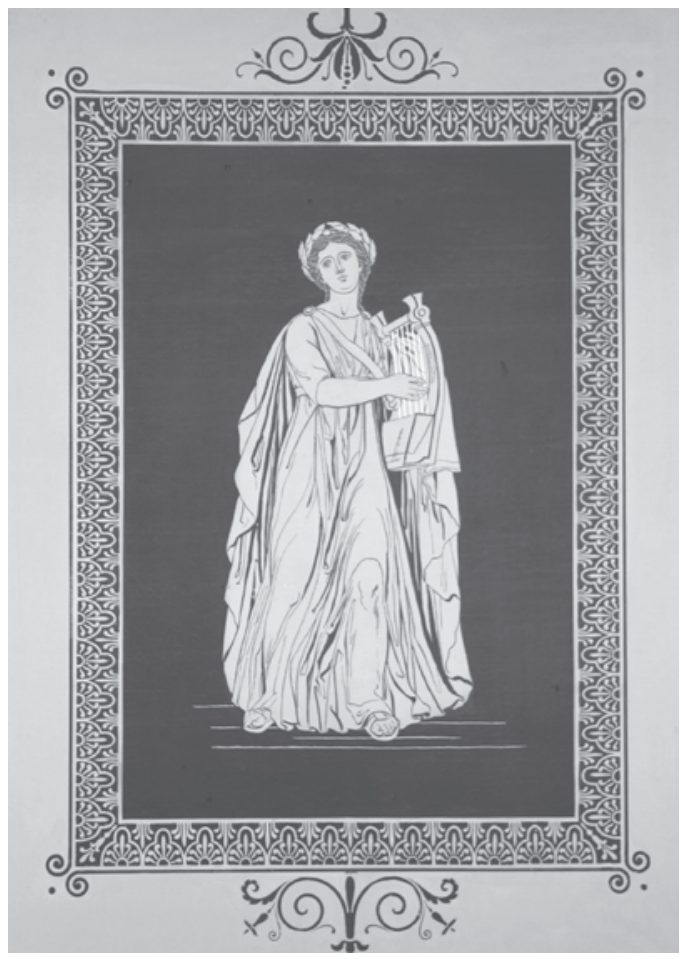

Abbildung 3: Apollon, die Kithara spielend (Göttinger Akademiezimmer) $^{36}$

des Triumphators hinzu. Vielleicht am ,nachhaltigsten', bis in die Gegenwart hinein, ist seit Petrarca die Idee des poeta laureatus geblieben.

Im Musenproömium Hesiods stellt, bis zum Einsatz der ,Kern-Theogonie (v. 116), eindeutig Zeus die dominante Gottheit dar. In dieses Beziehungsfeld hinein ist die „Götterentstehung“, als „Anfang der Welt", von vornherein komponiert. Die Musen tanzen um den Altar des Kronos-Sohnes Zeus (v. 4), sie besingen Zeus (v. 11). Athene wird eingeführt als Tochter des „aigistragenden“ Zeus (v. 13) (der Schild, den Hephaistos angefertigt hat - ein Epitheton, das schon bei Homer durchgängig die Stärke und Macht des obersten Gottes kennzeichnet). Nicht zuletzt sind die „olympischen“"Musen selbst Töchter des Zeus (mit dem gleichen Beiwort). Und auf die Dichterweihe des Hesiod folgt als erstes die Nennung eines Liedes der Musen auf Zeus (v. 36 ff.):

$\overline{36}$ Bergmann, Freigang, Eckardt [wie Anm. 35], S. 37. 
Nun denn, mit den Musen laßt uns beginnen,

Sie, die Zeus dem Vater mit ihrem Preisen

Erfreuen den großen Sinn, droben im Olymp,

Wenn sie sagen, was da ist, was sein wird,

Was vorher gewesen.

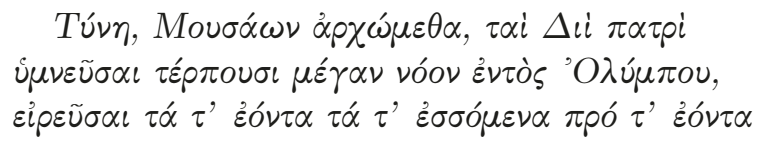

Die Geltung, der Anspruch, die Macht des Zeus ist, wie sich hier schon andeutet, in jeder Hinsicht, universal' ${ }^{\prime}$. Hesiod ist ein entschiedener, früher Anhänger dessen, was man die "Zeusreligion“ genannt hat, mit besonderer Betonung der „Gerechtigkeit“ (dike), über die unter den Menschen vor allem die (legitimen) Herrscher, die „Könige“ zu wachen haben ${ }^{37}$. In den Werken und Tagen ist das, auf besondere Weise, sozusagen juristisch pointiert (wegen des Erbrechtsstreits mit dem Bruder). Dike ist - nicht nur bei Hesiod - darüber hinaus Schlüsselbegriff für ,Ordnung' schlechthin. Das Lexem kosmos begegnet zwar bei Hesiod, wie bei Homer, nicht selten ${ }^{38}$, jedoch eher im Sinne von ,Rang', (militärischer) ,Ordnung', auch ,Schmuck' u. ä. Als, geordnetes Weltall', in Richtung auf den modernen Kosmosbegriff, läßt sich die Verwendung, zunächst vereinzelt, unter ,philosophischem ${ }^{\circ}$ Einfluß der Pythagoreer und dann der Stoiker beobachten (etwa seit dem 4. Jahrhundert). Und vollends kosmogonia als „Weltentstehung“ taucht erst im 1. Jahrhundert nach Christi Geburt auf. Solche begriffsgeschichtlichen Erinnerungen sind gelegentlich vonnöten, angesichts der Überfülle an modernen Neubildungen, die sich um kosmos herum etabliert haben.

Wie geht Hesiods Theogonie den Weg von Chaos und Gaia bis zur, Ordnung' der jetzigen Welt unter Zeus? Nicht zuletzt: Welchen Raum nimmt dabei das ,Erzählen' ein, und welche Modi des Erzählens sind kennzeichnend? Auf eine nach dem ,generativen " Prinzip gestaltete, gedrängte Passage über die weitere, Entstehungs'-Kette von den ,Urwesen' und den Abkömmlingen von Gaia und Kronos (darunter so wichtige wie Okeanos und so unbedeutende wie Koios und Kreios, aber auch Mnemosyne und Kronos) folgen noch ,Zwischenwesen “ wie die Kyklopen und die riesenhaften „Hundertarmigen" (v. 123-153). Nach nur kurzem Übergang schließen sich fast überraschend - zwei genau ausgearbeitete Erzähleinheiten an (man kann sie auch ,Teilmythen“ oder einfach ,Mythen' nennen). Sie haben sich

37 Über den im Deutschen leicht mißverständlichen Titel „König“ bei Hesiod (für griechisch basileus) vgl. das LfrgE [wie Anm. 20].

38 Wiederum: LfrgE. 
den Griechen und der westlichen Tradition, bis zur Malerei der Neuzeit, tief eingeprägt: die Entmannung des Uranos durch seinen Sohn Kronos, den Vater des Zeus (v. 154-187), und die Geburt der Aphrodite (v. 188206). Damit ist, aus gleich noch zu erläuternden Gründen, der erweiterte „Anfang" der Götter- und Welt-,Entstehung“ abgeschlossen.

Kronos, der ,Held' der ersten weit ausgreifenden Erzählung in der Theogonie überhaupt, wird auffallend früh, bereits in der ,proleptischen ' Kleinen Theogonie (v. 11 ff.), mit dem Aufmerksamkeit erregenden Beiwort „Krummes sinnend" (v. 18, so schon bei Homer) eingeführt; und wörtlich wieder in der ,Kern-Theogonie` (v. 123 ff.; dort v. 137). Am Anfang steht, als bloße ,Setzung', die düstere Feststellung, daß Uranos ,alle“ Kinder, die ihm Gaia gebiert, „haßt“ (v. 155; dort passivisch gefaßt) und versteckt. Charakteristisch, daß Gaia schon hier als physisches Zentrum der Welt und als Göttin handelt und daß kein Grund dafür genannt wird. Es ist das schon erwähnte Merkmal des ,Verschweigens' oder ,Aussparens' in mythischen Erzählungen (Versuche, hier psychologisierende Erklärungen anzusetzen, verfehlen gerade dies $)^{39}$. Gaia denkt sich einen „listigen, schlimmen Kunstgriff“ aus (v. 160). In drei Schritten, narrativ sorgfältig komponiert, wird die „List“ erwähnt, regelrecht, spannend', ohne Erläuterung. Gaia handelt nur, stellt als Element, als Werkstoff, grauen Stahl her und daraus eine „scharfgezahnte" große Sichel (v. 162, 175). Als sie die Kinder ermahnt, die Schandtaten des Vaters zu rächen (hier sogar in wörtlicher Rede), ermannt sich als einziger Kronos (erklärt sich bereit). Gaia „freut" sich (v. 173) und „unterweist" ihn in der „List“ (v. 175), die wieder nicht genannt wird. Als in der Nacht Uranos sich der Gaia zum Beischlaf nähert, packt Kronos mit der Linken die - nicht genannten - Geschlechtsteile des Vaters (v. 179-181):

Mit der Rechten aber faßte er fest

Die ungeheure Sichel, lang, scharfgezahnt,

Schwang sie und schnitt ab des eigenen Vaters Gemächte,

Und rückwärts warf er es, daß es hinter ihn fiel.

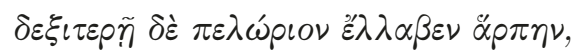

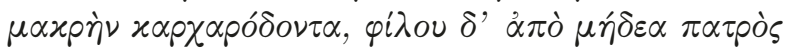

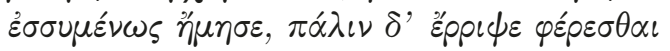

$\dot{\varepsilon} \xi o \pi i \sigma \omega$

Die Sichel, bäuerliches Gerät - zugleich der Welt Hesiods zugehörig - und Waffe, auch in anderen Mythen wie dem von Perseus und Medusa be-

39 Besonders häufig in Hesiod-Kommentaren (die entsprechende Stellen nicht unerläutert lassen wollen). 


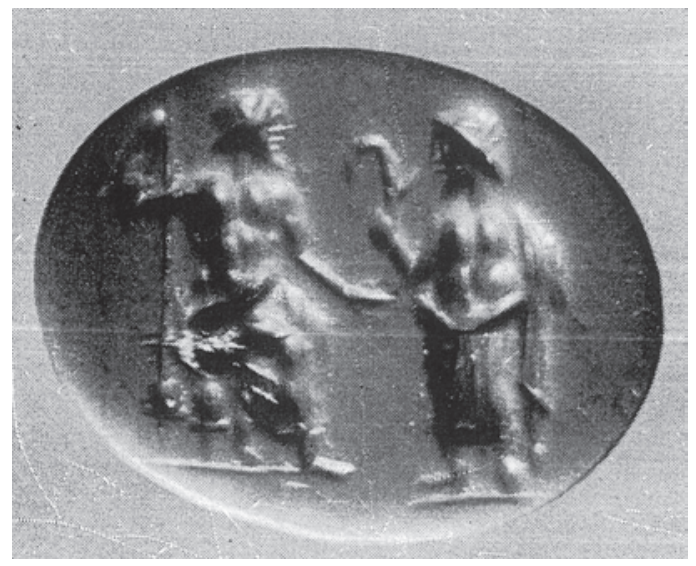

Abbildung 4: Kronos (r.) mit erhobener Sichel, vor seinem Vater Uranos. ${ }^{40}$

gegnend (ebenso in altorientalischen) wurde/war eindrückliches ,Attribut des Kronos (und bei den Römern das des Saat- und Fruchtbarkeitsgottes Saturn). Als furchterregendes Dingsymbol des Kronos trifft man es in der griechischen und dann der römischen Bildenden Kunst vielfältig an (ebenso auf Münzen), auch sich verselbständigend als mythisches Symbol: Hesiods herausragend plazierter Kronos-Mythos von der Kastration des eigenen Vaters wurde zu einer Schlüsselerzählung aus der „Entstehung“ der Götter und der Welt.

Warum ausgerechnet diese Erzählung, so prominent und detailliert herausgehoben, nachgerade inszeniert? Das ungeheure, schreckliche, folgenreiche Geschehen ist durch Narration ,gebannt', ein riesiger Schritt der Natur, im Sinne von Francis Bacon: der Kognition ein Stück weit geöffnet. Doch das vielleicht Entscheidende: Hinter diesem Mythos steht die alte, besonders auch im Vorderen Orient verbreitete Erzählung über die ,Trennung von Himmel und Erde ${ }^{\text {‘ }}$. Sie gehört essentiell noch zum „Anfang“ der Welt, im erweiterten Sinn. Interpreten hatten, seit längerem schon, hinter der Abfolge Uranos - Kronos - Zeus das Modell eines altorientalischen (auf Dynastieerzählungen basierenden) Sukzessionsmythos vermutet, bei Hesiod freilich mit deutlicher Teleologie auf Zeus hin gestaltet. Seit den 1950er Jahren sind aus hethitisch geschriebenen Keilschrift-Tafeln von Boghazköi (in denen sich zugleich ältere, auch mesopotamische Überlieferung spiegelt) zwei größere Texte bekannt, die unter den Titeln Mythos vom König-

40 Nach Lexicon Iconographicum Mythologiae Classicae. Bildlexikon der Antiken Mythologie. Bd. VI/1 [Textteil]. Zürich u. München 1992, S. 145; Bd. VI/2 [Bildteil], S. 66.

41 Vgl. Fritz Stolz: Artikel „Himmelsgott“. In: Handbuch religionswissenschaftlicher Grundbegriffe [wie Anm. 26]. Bd. 3 (1993), S. 141-143. 
tum im Himmel und Lied von Ullikummi gehandelt werden ${ }^{42}$. Für die Wege zu Hesiod werden unterschiedliche Annahmen diskutiert; die Herkunft des Vaters aus dem westlichen Kleinasien kann eine Rolle spielen. Hier relevant sind die fast programmatische Integration der - vergleichsweise sehr umfangreichen - Partie in den Eröffnungsteil der Großerzählung vom Anfang der Götter und der Welt und die Funktionalisierung im Sinne der Zeus-Religion: Die ,generative 'Linie führt vom „Chaos" über die ungeheuerliche, von „List“ bestimmte Gewalttat von (Gaia und) Kronos bis zur ,Ordnung' garantierenden Herrschaft des Zeus.

Der pragmatische und symbolische Akt, mit dem Kronos die abgetrennten Geschlechtsteile hinter sich wirft (v. 181; zumeist als ,apotropäische Handlung gedeutet), ist Dreh- und Angelpunkt für einen kurzen ,Zwischenakt' (v. 182-187: Entstehung der Erinyen, der Giganten und der Nymphen aus den Blutstropfen) und unmittelbar anschließend für den zweiten, kürzeren Teilmythos (v. 188-206): die Geburt der Aphrodite aus dem Schaum, den das "Gemächte" auf dem Meer verbreitet. Es ist eine Geburt ohne Zeugung (,Abstammung' freilich: von Uranos), von ferne vergleichbar der ,Kopfgeburt' Athenes aus dem Haupt des Zeus - wieder mythische ,Eigenkausalität', wie man es nennen könnte (die gelegentliche Bezeichnung der Geburt Aphrodites als „Parthenogenese“ ist irreführend). Wiederum wird die Zeitfolge, wie beim „Chaos“-Anfang und - extensiver beim Kronos-Mythos, erzählerisch-'pedantisch' entfaltet. Der doppelten, konkurrierenden Überlieferung vom Geburtsort der Aphrodite auf der Insel Kythera (vor der Südspitze der Peloponnes) und auf Kypros (Zypern) entsprechend ${ }^{43}$, treibt das „unvergängliche Fleisch“ von Westen nach Osten. Weißer Schaum bildet sich ringsum (aus dem griechischen Wort aphrós wird von Hesiod - in der schon erwähnten etymologisierenden Manier der Name erklärt). Aus ihm schreitet ein strahlendes Mädchen hervor, die Wiese ,schießt auf unter ihren schlanken Füßen (als Zeichen ihrer Fruchtbarkeit). Szenisch erzählte Epiphanie einer jungen Göttin, wie die einer Prinzessin (v. 201 f.):

Ihr gab Eros das Geleite,

Und Himeros (die Sehnsucht), der Schöne, folgte ihr,

Vom Anbeginn, wie sie erstanden war

Und wie sie zu der Götter Schar schritt.

42 Die Tafeln entstammen der 2. Hälfte des 2. vorchristlichen Jahrtausends. Auf Details muß hier verzichtet werden. Das Ullikummi-Lied wurde als ganzes zuerst 1952 veröffentlicht.

43 Auf beiden Inseln genoß Aphrodite sehr alte kultische Verehrung. Daher auch die bekannte Prädizierung Aphrodites als „Kythera-Geborene“ und als „Kypros-Geborene“. 


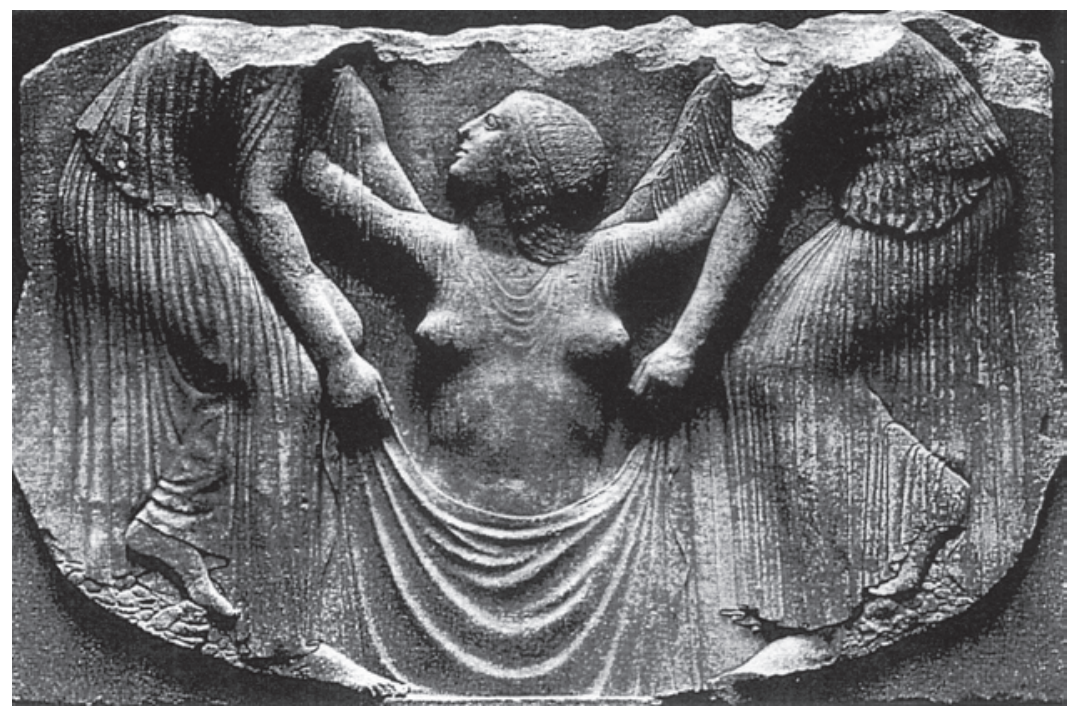

Abbildung 5: Die Geburt der Aphrodite ${ }^{44}$.

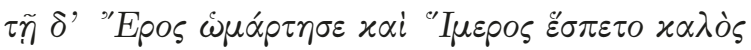

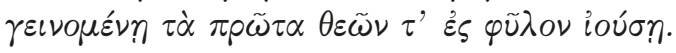

Ihr „Vorrecht“, ihr „Anteil“ unter den Menschen und Göttern liegt in dem, was sie wirken kann: „Mädchengeflüster und Lachen und Hintergehen Und süßes Erfreuen und Lust und Kosen“ (v. 205 f.). Danach wird mit der Geburt des „Verhängnisses“, des „Verderbens“, des „Todes“, des „Schlafs“ usw. der ,generative Faden wieder aufgenommen. Im scharfen Kontrast zum Schreckbild der Kronos-Tat hat sich die strahlende Geburt der Aphrodite ikonographisch vielfältig ausgeprägt. Eine ,rituelle' Variante aus dem 5. vorchristlichen Jahrhundert repräsentiert der sogenannte Ludovisische Thron (Abbildung 5).

Drei Beobachtungen zur Aphrodite-Erzählung Hesiods mögen erläutern, inwiefern diese Partie auf das Musenproömium und insbesondere auf den „Chaos“-Beginn der ,Kern-Theogonie` zurückverweist. Das Wirken der Götter bleibt unberechenbar, sowohl glanzvoll wie unheimlich („Hintergehen“ in der Liebe) - das, worauf das geordnete ,Erzählen“ der Mythen antwortet. Eros, der bereits im fünften Vers der eigentlichen Theogonie (v. 120) als eines der ,Urwesen“, ungezeugt, plötzlich „entstand“, kehrt

44 Nach: Lexicon Iconographicum Mythologiae Classicae [wie Anm. 40\}. Bd. II/1 [Textteil, 1984], S. 144; Bd. II/2 [Bildteil, 1984], S. 117. 
ringkompositorisch als Geleiter der Aphrodite wieder (v. 201). Er hat als ,Prinzip', wie man es verschiedentlich gedeutet hat, den gesamten entropischen Prozeß des Zeugens und Gebärens durchwirkt: nicht als Figur im Oberflächengeschehen, sondern - wie es in der neueren Erzählforschung französisch benannt wird ${ }^{45}-$ als in der ,Tiefe ${ }^{‘}$ Handelnder (als „actant“). Aphrodite, die alles Überstrahlende, deren stark altorientalische Prägung oft betont worden ist, erinnert an die babylonische Ishtar, der sich schließlich die konkurrierenden Göttinnen unterordnen müssen ${ }^{46}$. Sie bildet den Höhepunkt des Fundamentalteils der Theogonie. Und schließlich drittens: Auch sie erhält innerhalb des Pantheons ihr "Los“, ihren „Anteil“ (v. 203 f., ein in zahlreichen Mythologien resp. Religionen - auch etwa der altgermanischen - verankertes Muster). So fügt auch diese außergewöhnliche, herrliche und unheimliche Gottheit sich in eine ,Ordnung', über die Zeus wacht, die den gesamten Kosmos, die „Welt“ bestimmt.

Bei aller narrativen Eindrücklichkeit dieser beiden recht verschiedenartig gestalteten Mythen - hat Hesiod mit diesen Ausweitungen nicht sein klares generatives Prinzip des Erzählens vom „Anfang" durchbrochen? Eine Ungleichgewichtigkeit der Komposition ist nicht zu übersehen, die man je nach Einschätzung als ,archaisch ${ }^{647}$ oder auch als boiotisch-,provinziell ${ }^{6}$ kennzeichnen mag. Jedoch sind auch zwei Beobachtungen zur Tiefenstruktur von Belang. Die fast überdeutliche Voranstellung zweier Erzählungen besitzt etwas nachgerade Programmatisches: Auch vom frühesten Geschehen läßt sich elaboriert „erzählen“. Und beide Mythen sind innerhalb des Gesamtprojekts „Götterentstehung“ teleologisch gebunden, somit von kognitiver Qualität im Sinne Francis Bacons: Die Entmannung des Uranos (der seine Kinder versteckt und damit zugleich Gaia quält) öffnet den weiteren Prozeß des Zeugens und Gebärens, und über Kronos bereits den Weg zu Zeus ${ }^{48}$. Aphrodite wiederum verkörpert die strahlende Schönheit, die Unwiderstehlichkeit des Eros: und in ihm das Weiterwirken

45 Der Terminus „actant“ wurde durch den Linguisten und Semiotiker Algirdas Julien Greimas geprägt. Das deutsche Äquivalent „Aktant“ begegnet in verwirrend unterschiedlicher Verwendung.

46 Sie wird gelegentlich auch als „Supergöttin“ bezeichnet.

47 Das Epitheton (das hier bisher sparsam verwendet wurde) ist in der Hesiod-Literatur als Allerweltswort sehr verbreitet. Wegweisend für eine differenzierte Erfassung immer noch: Hermann Fränkel: Wege und Formen frühgriechischen Denkens. München ${ }^{2} 1960$.

48 Daß die Geburt des Zeus erst nach derjenigen der Aphrodite erzählt wird (v. 453 ff., neu ansetzend mit Kronos), gehört zu den charakteristisch ,archaischen 'Freiheiten der hesiodeischen Narration. 
des Prinzips (arché $)^{49}$ der sexuellen Lust als des immer neuen „Anfangs“ $(\text { arché })^{50}$.

Das lenkt zurück zu den Grundzügen des hesiodeischen Denkens am Beginn der ,Kern-Theogonie`. Die spekulative Leistung, unvermittelt „Chaos“ voranzustellen, als reine ,Setzung', und Eros als Weltprinzip wirken zu lassen, hat wesentlich dazu beigetragen, Hesiod zu einem Vorläufer, ja zum Archegeten der sogenannten „Vorsokratiker“ zu erklären (Thales, Anaximander, Heraklit, Parmenides u. a. $)^{51}$. Deren kritische Auseinandersetzung mit Hesiod geht auch aus der bloß fragmentarischen Überlieferung klar hervor. Dem „Chaos“ fehlt, wie bereits erläutert, im Gegensatz zu den nachfolgenden ,Urwesen ' und Gottheiten, jegliche Prädizierung. Gleichwohl hat man es immer wieder mit einer Substanz, und sei es einer diffusen, zu füllen gesucht ${ }^{52}$. Dabei geschieht die Anlehnung vorzugsweise an einen (oder mehrere) der „Vorsokratiker" und/oder an altorientalische Überlieferungen. So bei „Wasser“: an Thales von Milet (der Heimat des Hekataios) und an die "Urflut" und die "Wasser" der biblischen Genesis (v. 1, 1 f.), oder an die „Wassergötter“ des babylonischen kosmogonischen Epos Enuma elish. Oder „Nebel“. Oder „Dunkel“ (das bei Hesiod durch das Urwesen „Erebos“ bereits ,besetzt" ist). Die häufige Kennzeichnung als „leerer Raum " ${ }^{\text {"53 }}$ vermeidet zwar das Ansetzen einer Substanz, lehnt sich an die Physik des Aristoteles an ${ }^{54}$, führt jedoch mit "Raum" etwas ein, das sich als eigene Dimension im Text Hesiods nicht verankern läßt.

Man sollte sich entschließen, die Voraussetzungslosigkeit, das Nichtbestimmbare oder Noch-nicht-Bestimmbare des "Chaos“ als des „Anfangs" bei Hesiod stehen zu lassen und nicht sekundär, aufzufüllen'. Diese Voraussetzung seines Erzählens vom Anfang der Welt ist ebenso unabweisbar wie das Fehlen jeglicher Vorstellung von einem "Schöpfer ${ }^{\text {"55 }}$. Auch wenn aus Berührung mit vorgriechisch-mediterranen oder altorientalischen Traditionen solche ,Ideen' hier und da andeutungsweise bekannt gewesen sein

\footnotetext{
49 Diese (nach-hesiodeische) Bedeutung, die sich in der ionischen Naturphilosophie herausbildet, manifestiert sich am einfachsten im lateinischen principium (,An-fang').

50 So wiederholt bei Hesiod im ,Neuansetzen' des Rhapsoden (v. 1!, dann wieder v. 35 usf.) und innerhalb der "generativen“ Kette. Zur Semantik im einzelnen s. LfrgE [wie Anm. 17].

51 Dies vor allem seit dem Ende des Zweiten Weltkriegs; bezeichnend: Olof Gigon: Der Ursprung der griechischen Philosophie von Hesiod bis Parmenides. Basel 1945.

52 Zwischensummen: Robert Mondi: XAO $\Sigma$ and the Hesiodic Cosmogony. In: Harvard Studies in Classical Philology 92 (1989), S. 1-41; Aude Wacziarg: Le Chaos d'Hésiode. In: Pallas, Revue d'études antiques. Toulouse 2001, S. 131-152.

53 Vgl. Anm. 52.

54 Wie Anm. 10.

55 Die Entwicklungsstufen übersichtlich bei Carl J. Classen: The creator in Greek thought from Homer to Plato. In: Classica \& Mediaevalia 27 (1964), S. 1-22.
} 
mögen - für Hesiod wie für das frühgriechische Denken insgesamt gehören sie nicht zum engeren Horizont. Zugespitzt formuliert: er ist nichtkreationistisch ${ }^{56}$. Der Demiurg (demiurgós), als „Weltschöpfer“, gewinnt erst im 4. Jahrhundert, wesentlich durch Platon (im Timaios) an Bedeutung, mit Schwergewicht dann im christlichen Platonismus ${ }^{57}$.

Hesiod ist auf der ,heidnischen' Seite zu belassen - was, wie erwähnt, einzelne Analogien zur biblischen Genesis nicht ausschließt, auch in den ,erzählerischen ${ }^{\prime} Z$ ügen ${ }^{58}$. Dazu eine letzte Beobachtung. Das griechische chaos läßt sich als "gähnende Leere" übersetzen (wie oben), aber auch etwa als "gähnender Schlund" wie beim Krokodil, bei der Riesenschlange und anderen Monstern (auch in der griechischen Bildenden Kunst), oder beim alttestamentlichen Leviathan, der ja häufig auch als „Chaosschlange“ bezeichnet wird, unter mehr oder weniger klarer Anspielung auf das „Chaos" Hesiods. Es geht nicht darum, durch die Hintertüre doch noch etwas ,Substantielles` einzuführen.

Doch eine Konnotation ${ }^{59}$ ist zu erwägen: der „Schrecken“, den die Vorstellung eines tierhaft aufgerissenen Riesenschlundes hervorruft ${ }^{60}$. Das mythische Erzählen im Sinne Francis Bacons bewegt sich bei Hesiod von einem irritierenden Anfang des nicht bestimmbaren, Noch nicht' über ein ungreifbares Urgeschehen des „Entstehen“" (in der Tiefe vom Prinzip des „Eros“ gelenkt), über grausige Erzählungen von den Schandtaten des Uranos ${ }^{61}$ und von dessen Entmannung durch den eigenen Sohn, schließlich auf den Kosmos des Zeus hin.

Der „Schrecken“, den diese Erzählungen als ,eingreifende“ Wirkung erzeugen (das Motiv des ,Erschreckens' begegnet in der Kronos-Erzählung auch textimmanent, v. 167) ${ }^{62}$, ist zurückgebunden an den primordialen „Schrecken“, den die bedrohliche Übermacht der undurchschauten Natur-

\footnotetext{
56 Die ausdrückliche Ablehnung eines Schöpfergottes begegnet bereits bei Heraklit.

57 Die zentrale Stelle bei Platon: Timaios 41a ff.

58 So etwa schon in der Paradies-Erzählung (Genesis 2, 46-25, dem älteren Teil - des sogenannten "Jahwisten" - zugehörig).

59 Im genaueren Sinn, wie ihn etwa Umberto Eco aus der Linguistik in die kulturwissenschaftliche Semiotik übernommen hat.

60 Also nicht strikt tiergestaltig (theriomorph) nach einer bestimmten Spezies, sondern nur ,tierartig' (therioid) mit Konnotation eines speziesübergreifenden Merkmals (Pranke, aufgerissener Schlund u. dgl.).

61 Gaia selbst bewertet gegenüber den Kindern die Taten des Vaters gleich doppelt als „schlimmen Frevel“ (v. 165), als gegen das (,sozial-moralisch') „Schickliche“, „Natürliche“ verstoßend (die Nähe zur dike ist evident).

62 Als Gaia ihre Kinder für eine „Rache“ an dem ruchlosen Vater zu gewinnen versucht (ohne dies zu konkretisieren), werden sie von „Furcht“, „Schrecken“ ergriffen (v. 167), und ihre Reaktion ist - Verstummen (nur Kronos wagt sich heraus).
} 
gewalten erregt. Neuere Mythostheorien ${ }^{63}$ haben dieser Urmotivation besondere Aufmerksamkeit zugewandt, haben gar von „Urangst“ gesprochen $^{64}$. So weit braucht man nicht zu gehen. Das Anfangs,,-Chaos" des Hesiod, wie es hier verstanden wurde, als nicht sekundär mit ,Substanz aufgefülltes, schließt zwei Potenzen ein: das Bedrohliche (mit oder ohne die erwähnte Konnotation) und den zu Beginn erörterten Impuls des Fragens nach dem ,Davor'.

„Chaos" im Sinne Hesiods ist nicht selbst schon erzählbar. Insofern bleibt die Paradoxie des oben gesetzten Titels. Erzählbar aber ist, was danach geschieht: was durch das Prinzip der "Genesis“ sozusagen ,von rückwärts an die Uranfänglichkeit des „Chaos“ angebunden bleibt (durch das naive „entstand“, v. 116). Oder modern formuliert: an dessen „Anfangssingularität ${ }^{\text {“65 }}$, die sich durch das Fehlen jeglicher vorgängigen Analogie- oder Vergleichsgrößen auszeichnet. Die Phantasie hat gleichwohl ein sogenanntes „Vorausuniversum“ schon zu denken versucht. Das Irritierende, das bei Hesiod als uranfänglicher „Schrecken“ anzusetzen sein mag, könnte sein spezifisch neueres Pendant darin erhalten, daß im Big Bang statt einer „Explosion" nunmehr auch eine gewaltige "Implosion" gedacht wird ${ }^{66}$, nicht erst (wie andere annehmen) am „Ende“ der Welt - und vice versa.

Hesiod, um 700 vor Christi Geburt, repräsentiert selbst ,Anfangssingularität'. Er sagt nicht: „Ganz am Anfang war Chaos“ (es war auch kein Schöpfer). Sondern: „Ganz am Anfang entstand Chaos“ - ein ambitionierter Versuch, das Unheimliche des Anfangs durch den Beginn von Erzählen, dann durch generative Mythen an den Zusammenhang des Lebendigen zu binden.

63 Die Forschungsgruppe „Poetik und Hermeneutik“ stellte eine ihrer frühen Schlüsselpublikationen zur Mythenrezeption (wesentlich unter Einwirkung von Hans Blumenberg) unter den Titel: Terror und Spiel. Probleme der Mythenrezeption. Hrsg. v. Manfred Fuhrmann (Poetik und Hermeneutik. IV). München 1971 (statt „Terror“ begegnet in dem Band als wichtigstes Synonym auch „Schrecken“). Beispiele hierzu, bis zum Ausgang des 20. Jahrhunderts, in: Texte zur modernen Mythentheorie. Hrsg. v. Wilfried Barner, Anke Detken u. Jörg Wesche. Stuttgart 2003.

64 Jamme [wie Anm. 27], S. 88 ff. führt dies bis auf Vico zurück.

65 Nicht im engeren Sinne der Theorien der Kosmophysik, die sich dadurch auszeichnen, daß sich die Determinanten des Anfangs mathematisch abstrakt formulieren lassen, ohne daß die Dimension der Zeit schon gegeben wäre.

66 Eine Interdependenz der Annahmen über „Anfang" und „Ende“/,Zukunft" wird wiederholt erkennbar in der knappen Zusammenstellung von Hans-Joachim Blome u. Harald Zaun: Der Urknall. Anfang und Zukunft des Universums. München ${ }^{2} 2007$. 